Research Article

\title{
Prevalence and Molecular Genetics of Methicillin-Resistant Staphylococcus aureus Colonization in Nursing Homes in Saudi Arabia
}

\author{
Ahmed Albarrag, ${ }^{1}$ Ashwag Shami $\mathbb{D D}^{2}{ }^{2}$ Abrar Almutairi, ${ }^{2}$ Sara Alsudairi, ${ }^{2}$ Sumayh Aldakeel, ${ }^{1}$ \\ and Amani Al-Amodi ${ }^{1}$ \\ ${ }^{1}$ Department of Pathology, School of Medicine, King Saud University, Riyadh, Saudi Arabia \\ ${ }^{2}$ College of Science, Princess Nourah Bint Abdulrahman University, Riyadh, Saudi Arabia \\ Correspondence should be addressed to Ashwag Shami; ayshami@pnu.edu.sa
}

Received 2 December 2019; Accepted 20 May 2020; Published 3 June 2020

Academic Editor: Maria Luisa Ricci

Copyright (c) 2020 Ahmed Albarrag et al. This is an open access article distributed under the Creative Commons Attribution License, which permits unrestricted use, distribution, and reproduction in any medium, provided the original work is properly cited.

\begin{abstract}
Objective. Methicillin-resistant Staphylococcus aureus (MRSA) is one of the main causative agents of nosocomial infections that has posed a major threat to those with compromised immune systems such as nursing home residents. The aim of this study was to determine the rates of MRSA strains and the types of Staphylococcal Cassette Chromosome mec (SCCmec)in nursing homes in Saudi Arabia. Methods. A total of 188 nasal swabs were collected from the residents and nursing staff in two nursing homes in Riyadh, Saudi Arabia. All MRSA isolates were tested for antimicrobial susceptibility and analyzed for mecA and SCCmec typing by multiplex PCR assay. Detection of the Panton-Valentine leukocidin ( $P V L)$ gene was also tested in all positive MRSA isolates by multiplex PCR using specific primers. Results. Among the 188 collected nasal swabs (105 males and 83 females), MRSA colonization rate was $9.04 \%$ (11 (5.85\%) females and 6 (5.71\%) males). About $47 \%$ of MRSA were multidrug resistant (MDR) as acquired resistance to beta-lactam, macrolide, and aminoglycoside antibiotics. However, all the MRSA isolates showed susceptibility to vancomycin, tigecycline, and linezolid. All the MRSA isolates $(n=17)$ were mecA-positive with the SCCmec IVc $(n=7,41.18 \%)$ as the most common SCCmec type followed by SCCmec V $(n=5,29.41 \%)$ and SCCmec IVa $(n=2,11.76 \%)$. The remaining isolates $(n=3)$ were nontypeable $(17.65 \%)$. In addition, the PVL toxin gene was only detected in four of the male samples. Conclusion. MRSA nasal colonization is a common incident among nursing home residents. The prevalence of community-associated (CA) MRSA (SCCmec IV and V) was more common than hospital-associated (HA) MRSA in our study samples. It is crucial to investigate such rate of incidence, which is a key tool in preventive medicine and would aid in determining health policy and predict emergent outbreaks.
\end{abstract}

\section{Introduction}

Staphylococcus aureus, especially methicillin-resistant S. aureus (MRSA), is one of the main nosocomial pathogens associated with morbidity and mortality in both hospital and community settings [1]. According to the Center for Disease Control and Prevention (CDC), MRSA have resulted in almost 11,000 deaths in 2011 [2]. The prevalence of MRSA in nursing homes varied substantially from $1 \%$ to $23 \%$ between countries in Europe [3]. Nursing homes have been denoted to increase MRSA transmission and infection due to their propensity to admit old-age residents with premorbid conditions and weakened immune systems [4-6]. A 2005 cross-sectional survey carried out by a Belgian cohort demonstrated that, on average, $19 \%$ of the screened nursing home residents were MRSA carriers [7].

S. aureus isolates have gained resistance to methicillin due to the Staphylococcal cassette chromosome SCCmec genetic element integrated into $S$. aureus genomic chromosomal DNA downstream the orf X gene [8]. This cassette contains the methicillin resistance ( $m e c A)$ gene, which is responsible for resistance to antibiotics such as methicillin, 
penicillin, and other penicillin-like antibiotics and additional antibiotic resistance determinants [8]. Compellingly, studies have proven a strong correlation between MRSA strains and their accrued resistance to commonly used groups of antibiotics such as tetracycline, fluoroquinolones, aminoglycosides, chloramphenicol, and macrolides [9].

The level of resistance to non- $\beta$-lactam antibiotic classes varies between strains that are produced by either health care-associated (HA) MRSA or community-associated (CA) MRSA [10]. CA-MRSA strains differ from HA-MRSA genotypically and phenotypically. CA-MRSA harbors relatively smaller staphylococcal cassette chromosomal mec (SCCmec), which is a cassette that contains the mecA gene, type IV (21 to $24 \mathrm{~kb})$ or type V (28 kb) [10-12]. In contrast, HA-MRSA strains usually contain larger SCC mec belonging to type I ( $34 \mathrm{~kb})$, II (53 kb), or III (67 kb) [12]. These larger elements also contain the mecA gene and are resistant to more non- $\beta$-lactam classes of antimicrobials [10]. PVL is a virulence factor, which belonging to the family of synergohymenotropic toxins, which has an important role in pathogenicity by producing pores in the membrane of host defense cells [12].

The aim of this study is to investigate the rate of MRSA colonization in nursing homes in Saudi Arabia by isolating $S$. aureus and molecular identification of the of SCCmec types, detection of the mecA resistance gene, and the virulence gene $P V L$.

\section{Materials and Methods}

2.1. Sample Collection. This study was authorized by the Medical Ethic Committee of Princess Nourah Bin Abdulrahman University (IRB number 17-0046). A total of 188 individuals (105 males and 83 females) aged from 39 up to 104 residing in a nursing home in Riyadh, Saudi Arabia, were screened for MRSA colonization after obtaining informed consent from the residents and nursing staff. Amies transport swabs were used to sample the anterior nares of residents. The swabs were processed within 2 hours of collection. All swabs were cultured/cultivated on mannitol salt agar with oxacillin (MSAO) media for $24 \mathrm{hrs}$ at $37^{\circ} \mathrm{C}$ to screen for MRSA. Following 24 hours of incubation, presumptive MRSA colonies were subcultured on blood agar for further identification by coagulase testing and standard microbiological methods.

2.2. Identification and Antimicrobial Susceptibility Testing. Identification and antimicrobial susceptibility testing was performed on all presumptive MRSA isolates by the automated method VITEK 2 (BioMérieux, Inc., Durham, NC) using AST580-GP in accordance with the manufacturer's instructions. The interpretation of susceptibility testing was performed based on the clinical breakpoints following Clinical and Laboratory Standards Institute (CLSI).

2.3. SCCmec Typing and PCR-Based Assays for the PVL Gene. Genomic DNA extraction from the MRSA isolates was done using QIAamp DNA Mini Kit (Qiagen, Germany) in accordance with manufacturers' instructions. The template DNA was used in a multiplex polymerase chain reaction (mPCR) to characterize and identify the Staphylococcal Cassette Chromosome (SCC) mec types I-V for MRSA as described by McClure-Warnier [13]. Additionally, a multiplex PCR assay was performed that targets the $16 \mathrm{~S}$ rRNA gene, the lukS/F-PV genes, which encode PVL, and the mecA gene as described by McClure et al. [14]. All PCR products were visualized on a $1 \%$ agarose gel stained with ethidium bromide.

\section{Results}

Among the 188 collected nasal swabs, 20 swabs grown presumptive MRSA colonies on mannitol salt agar with oxacillin (MSAO). Of these 20 samples, 17 were coagulasepositive, which further identified as $S$. aureus using the VITEK 2 automated identification system. This indicates a 9.04\% rate of nasal colonization with MRSA. Among the 17 MRSA carriers, $11(13.25 \%(11 / 83))$ were females and 6 $(5.71 \%(6 / 105))$ were males with a mean age of 62.45 (age range $39-104$ years).

The antimicrobial susceptibility testing by the VITEK 2 automated method is determined for benzylpenicillin, cloxacillin, oxacillin, cefaclor, erythromycin, clindamycin, gentamicin, fosfomycin, levofloxacin, teicoplanin, tetracycline, vancomycin, tigecycline, and linezolid (Table 1). About $47 \%$ of MRSA were multidrug resistant (MDR) as acquired resistance to beta-lactam, macrolide, and aminoglycoside antibiotics. However, all the MRSA isolates showed susceptibility to vancomycin, tigecycline, and linezolid.

Identification of methicillin resistance strains was confirmed by the detection of the mecA gene in a multiplex PCR. All the 17 MRSA isolates had a PCR product of $310 \mathrm{bp}$ corresponding to the size of the amplified DNA fragment of the mecA gene (Figure 1). SCCmec typing of these 17 MRSA isolates was performed by the multiplex PCR. The most common type among all isolates was SCCmec IVc $(n=7$, $41.18 \%)$ followed by SCCmec V $(n=5,29.41 \%)$ and SCCmec IVa $(n=2,11.65 \%)$. The remaining isolates $(n=3)$ were nontypeable (17.65\%) (Table 2).

In addition, the virulence gene, PVL, was also detected (Figure 1). Of the 17 MRSA isolates, four of the male samples (66.67\% (4/6)) were PVL-positive, while all the female samples were PVL-negative. Three of the PVL-positive isolates were elderly individuals and one was a nurse, yet all the four isolates had the SCCmec IVc subtype (57.14\% (4/7)) (Figure 2).

\section{Discussion}

Controlling MRSA strains' dissemination within nursing homes is challenging [15]. The documented prevalence rates of MRSA in nursing homes vary from 1-23\% $[3,16]$. In our study, the prevalence rate of MRSA colonization in nursing homes is $9 \%$, which characterizes a moderate threat. Effective approaches such as surveillance assessments of MRSA classification are required to meet the need of controlling MRSA dissemination. This could be achieved 
TABLE 1: Antibiotic resistant profile of MRSA isolates from elderly residents and nurses.

\begin{tabular}{|c|c|c|c|c|c|}
\hline \multirow[b]{2}{*}{ Antimicrobial agent } & \multirow[b]{2}{*}{ MIC range $(\mu \mathrm{g} / \mathrm{mL})$} & \multirow[b]{2}{*}{$\begin{array}{c}\text { Resistant } \\
(n=17) \\
n(\%)\end{array}$} & \multicolumn{3}{|c|}{ MRSA SCCmec types $(n=14)$} \\
\hline & & & $\begin{array}{c}\text { IVa } \\
(n=2) \\
n(\% \mathrm{R})\end{array}$ & $\begin{array}{c}\text { IVc } \\
(n=7) \\
n(\% \mathrm{R})\end{array}$ & $\begin{array}{c}\mathrm{V} \\
(n=5) \\
n(\% \mathrm{R})\end{array}$ \\
\hline Benzylpenicillin & $>=0.5$ & $17(100)$ & $2(100)$ & $7(100)$ & $5(100)$ \\
\hline Cloxacillin & $>=0.5$ & $17(100)$ & $2(100)$ & $7(100)$ & $5(100)$ \\
\hline Oxacillin & $0.25-4$ & $17(100)$ & $2(100)$ & $7(100)$ & $5(100)$ \\
\hline Cefaclor & $0.25-4$ & $17(100)$ & $2(100)$ & $7(100)$ & $5(100)$ \\
\hline Gentamicin & $0.50-16$ & $8(47.06)$ & $1(50)$ & $4(57.14)$ & $1(20)$ \\
\hline Levofloxacin & $0.12-8$ & $3(17.65)$ & $0(0.0)$ & $1(14.28)$ & $1(20)$ \\
\hline Erythromycin & $0.25-8$ & $10(58.82)$ & $2(100)$ & $5(71.43)$ & $2(40)$ \\
\hline Clindamycin & $0.25-8$ & $9(52.94)$ & $1(50)$ & $5(71.43)$ & $2(40)$ \\
\hline Teicoplanin & $0.50-32$ & $1(5.88)$ & $0(0.0)$ & $0(0.0)$ & $0(0.0)$ \\
\hline Vancomycin & $0.50-2$ & $0(0.0)$ & $0(0.0)$ & $0(0.0)$ & $0(0.0)$ \\
\hline Tetracycline & $1-16$ & $1(5.88)$ & $1(50)$ & $0(0.0)$ & $0(0.0)$ \\
\hline Tigecycline & $0.12-0.5$ & $0(0.0)$ & $0(0.0)$ & $0(0.0)$ & $0(0.0)$ \\
\hline Fosfomycin & 8-128 & $4(23.52)$ & $1(50)$ & $2(28.57)$ & $0(0.0)$ \\
\hline Linezolid & $1-4$ & $0(0.0)$ & $0(0.0)$ & $0(0.0)$ & $0(0.0)$ \\
\hline
\end{tabular}

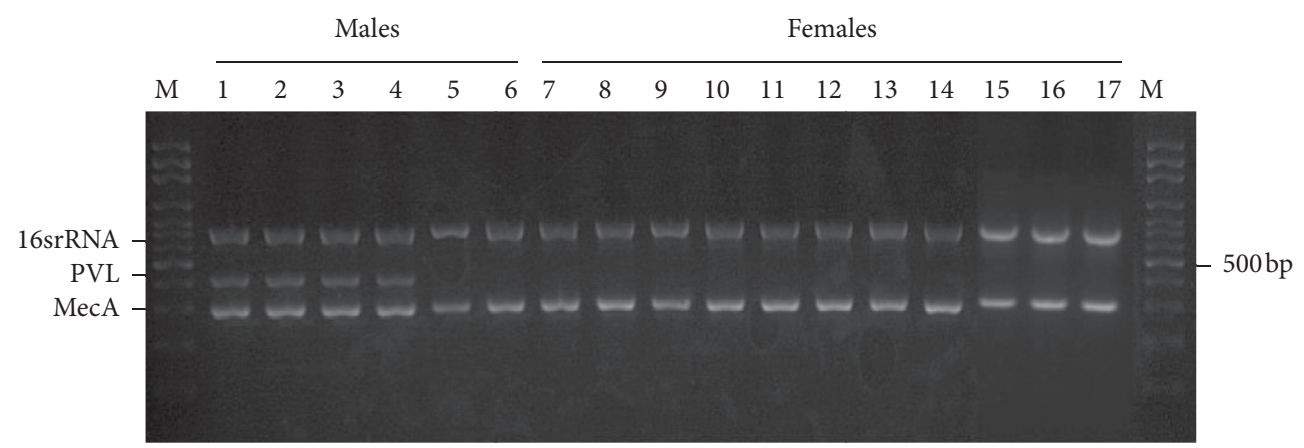

Figure 1: Multiplex PCR assay for the detection of PVL and mecA genes. M: $100 \mathrm{bp}$ DNA marker, lanes 1 to 6: MRSA isolates from men, and lanes 7 to 17: MRSA isolates from women. 16 srRNA: $16 \mathrm{~S}$ rRNA gene amplicon (762 bp), PVL: lukS/F-PV amplicon (433 bp), and MecA: $m e c A$ amplicon $(310 \mathrm{bp})$.

TABle 2: mecA gene, PVL gene, and SCCmec types in MRSA isolates.

\begin{tabular}{|c|c|c|c|c|c|}
\hline Sample ID & Gender & Residential type & SCCmec type & mecA gene & PVL gene \\
\hline 1 & \multirow{6}{*}{ Male } & $\mathrm{E}$ & IVc & + & + \\
\hline 2 & & $\mathrm{E}$ & IVc & + & + \\
\hline 3 & & $\mathrm{E}$ & IVc & + & + \\
\hline 4 & & $\mathrm{~N}$ & IVc & + & + \\
\hline 5 & & $\mathrm{~N}$ & - & + & - \\
\hline 6 & & $\mathrm{~N}$ & $\mathrm{IVc}$ & + & - \\
\hline 7 & \multirow{11}{*}{ Female } & $\mathrm{E}$ & $\mathrm{V}$ & + & - \\
\hline 8 & & $\mathrm{E}$ & $\mathrm{V}$ & + & - \\
\hline 9 & & $\mathrm{E}$ & IVa & + & - \\
\hline 10 & & $\mathrm{E}$ & $\mathrm{V}$ & + & - \\
\hline 11 & & $\mathrm{E}$ & $\mathrm{V}$ & + & - \\
\hline 12 & & $\mathrm{E}$ & IVa & + & - \\
\hline 13 & & $\mathrm{E}$ & $\mathrm{V}$ & + & - \\
\hline 14 & & $\mathrm{E}$ & - & + & - \\
\hline 15 & & $\mathrm{E}$ & IVc & + & - \\
\hline 16 & & $\mathrm{E}$ & IVc & + & - \\
\hline 17 & & $\mathrm{E}$ & - & + & - \\
\hline
\end{tabular}

E: elderly and N: nurse.

through the detection of $m e c A$ gene carriers and all the SCCmec types. This is the first study to be conducted in Saudi Arabia aiming to assess nasal carriage prevalence of MRSA colonization in residential care homes for the elderly through molecular identification of SCCmec typing, mecA resistance gene, and virulence gene PVL. 


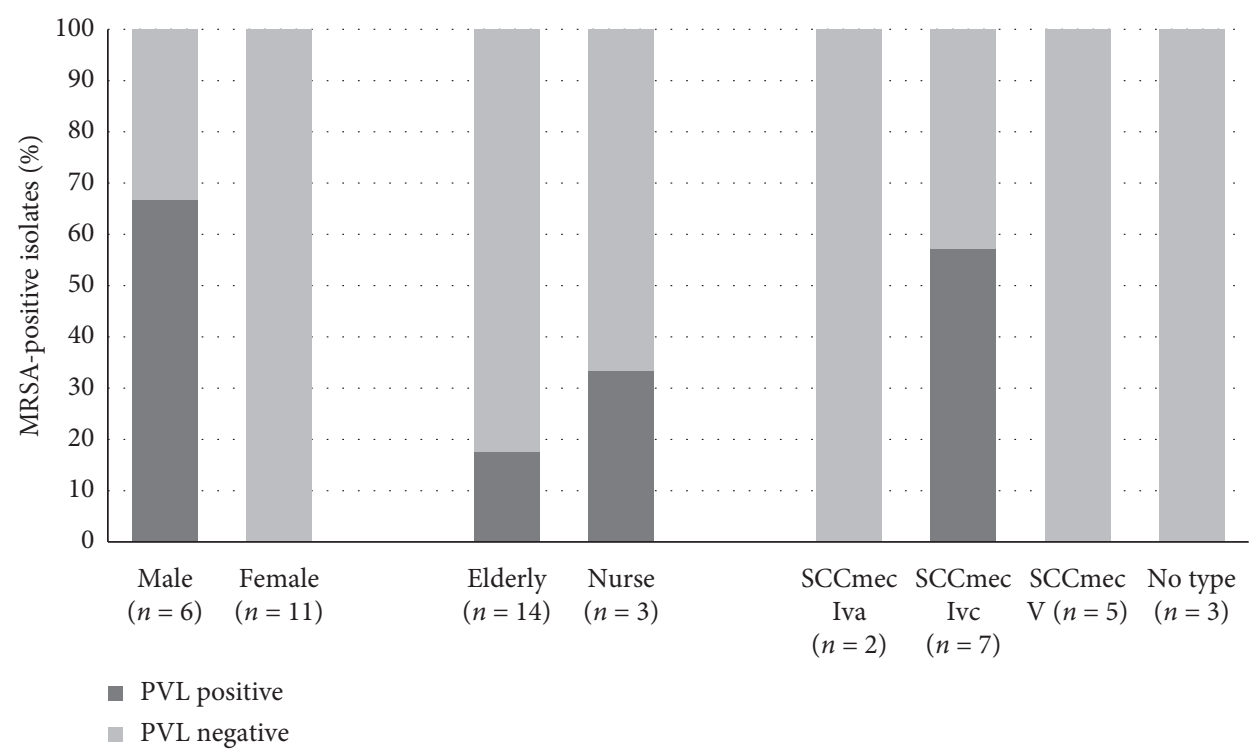

FIGURE 2: Frequency of methicillin-resistant Staphylococcus aureus (MRSA) colonization in positive and negative PVL isolates. Four male samples were positive for PVL $(66.67 \%(4 / 6))$. Three $(21.43 \%(3 / 14))$ were elderly and one $(33.33 \%(1 / 3))$ was a nurse. The 4 PVL-positive isolates were all SCCmec-IVc $(57.14 \%(4 / 7))$.

Our data demonstrated that gender was not associated with MRSA colonization compared to previous studies, where males were predominantly associated with MRSA colonization [17-20]. The resistance profile revealed lower resistance rates compared to the average of resistance reported previously especially for gentamicin, erythromycin, tetracycline, fosfomycin, and linezolid [9].

Since all the isolates were oxacillin-resistant, it was expected to observe the acquisition of the methicillin resistance gene mecA in all isolates. SCCmec typing was performed on the isolates in which $10(66.6 \%)$ were SCCmec type IV and 5 (33.3\%) were SCCmec type V. These two most common types of SCCmec, IV and V, were carried by MRSA strains presumably due to their relatively small size that facilitates their spread among MRSA strains [21]. Reported MRSA SCCmec types have no influence on the antibiotic resistant pattern of MRSA isolates. In addition to the mecA gene, four isolates were carrying the PVL gene which is linked with virulence; the PVL toxin has been associated with many of the severe clinical presentations of MRSA infection.

It is worth noting that based on the molecular analysis of SCCmec, isolates show hallmarks of being a communityassociated (CA) MRSA strain type. The frequent admissions of institutionalized elderly members of the community to the acute care hospitals expose them regularly to MRSA dissemination. However, in our study, none of the MRSA isolates were harboring health care-associated (HA) MRSA strain types; in contrast, subjects were all colonized by either SCCmec IV or V types. Since these cassettes are mainly associated with (CA) MRSA, it is hard to rule out the emergence of MRSA into this long-term care facility from the community. This has been documented worldwide by others who have reported a slow emergence of CAMRSA strain types in nursing homes [6, 22-25]. On the contrary, PVL toxin gene is a community marker, and it was observed in $23.53 \%(4 / 17)$ of the isolates, which is relatively low compared to the rates of carriage of the PVL in CA-MRSA strains, $>75 \%$ [26]. Collectively, this would all suggest an acquisition of a concurrent distribution of both community- and hospital-associated MRSA in nursing homes. Further studies using well-established methods such as pulse-field gel electrophoresis (PFGE) or staphylococcal protein A (spa) typing methods to genotype MRSA isolates would facilitate determining strain relatedness, evolutionary patterns, and source of transmission more accurately [27].

The limitations of our study were mainly driven by including a relative small number of subjects especially with respect to MRSA colonization. Larger sample sizes from multiple community nursing homes are required to accurately depict the picture of MRSA prevalence in Saudi Arabia. Additionally, the extent of CA-MRSA colonization among nursing home residents cannot be determined as this study was not conducted as a point prevalence survey that includes all the nursing home residents. However, the revealed data raise the concern regarding the introduction of these strain types to the long-term care residents.

This study showed incidence of nasal carriage of CAMRSA in nursing homes in Saudi Arabia denoting an essential indicator of strain prevalence. Investigation of such rate of incidence is a key tool in preventive medicine, assisting health care legislators in determining health policy and predicting emergent outbreaks. The introduction of CAMRSA strains in this setting will likely change the selection of empirical antibiotic therapies for MRSA infections. Also, it could pose growing problems in the severity of these staphylococcal infections in the immunocompromised residents. 


\section{Data Availability}

All data that were used to support the findings of this study are included within the article.

\section{Conflicts of Interest}

The authors declare that they have no conflicts of interest.

\section{Authors' Contributions}

Ahmed Albarrag and Ashwag Shami contributed equally to this work.

\section{Acknowledgments}

This research was funded by the Deanship of Scientific Research at Princess Nourah Bint Abdulrahman University through the Fast-track Research Funding Program.

\section{References}

[1] P. Loomba, J. Taneja, and B. Mishra, "Methicillin and vancomycin resistant $S$. aureus in hospitalized patients," Journal of Global Infectious Diseases, vol. 2, no. 3, p. 275, 2010.

[2] R. Dantes, Y. Mu, R Belflower et al., "National burden of invasive methicillin-resistant Staphylococcus aureus infections, United States, 2011," JAMA Internal Medicine, vol. 173, no. 21, p. 1970, 2013.

[3] M. Dulon, F. Haamann, C. Peters, A. Schablon, and A. Nienhaus, "MRSA prevalence in European healthcare settings: a review," BMC Infectious Diseases, vol. 11, no. 1, p. 138, 2011.

[4] V. W. Chuang, I. H. Tsang, J. P. Keung et al., "Infection control intervention on meticillin resistant Staphylococcus aureus transmission in residential care homes for the elderly," Journal of Infection Prevention, vol. 16, no. 2, pp. 58-66, 2015.

[5] P. Vovko, M. Retelj, T. Z. Cretnik et al., "Risk factors for colonization with methicillin-resistant Staphylococcus aureus in a long-term-care facility in Slovenia," Infection Control \& Hospital Epidemiology, vol. 26, no. 2, pp. 191-195, 2005.

[6] A.-M. Kerttula, O. Lyytikainen, J. Vuopio-Varkila et al., "Molecular epidemiology of an outbreak caused by methicillin-resistant Staphylococcus aureus in a health care ward and associated nursing home," Journal of Clinical Microbiology, vol. 43, no. 12, pp. 6161-6163, 2005.

[7] B. Jans., D. Schoevaerdts., T.-D. Huang et al., "Epidemiology of multidrug-resistant microorganisms among nursing home residents in Belgium," PLoS One, vol. 8, no. 5, Article ID e64908, 2013.

[8] K. Hiramatsu, Y. Katayama, H. Yuzawa, and T. Ito, "Molecular genetics of methicillin-resistant Staphylococcus aureus," International Journal of Medical Microbiology, vol. 292, no. 2, pp. 67-74, 2002.

[9] D. Kaur and S. Chate, "Study of antibiotic resistance pattern in methicillin resistant Staphylococcus aureus with special reference to newer antibiotic," Journal of Global Infectious Diseases, vol. 7, no. 2, pp. 78-84, 2015.

[10] M. Z. David and R. S. Daum, "Community-associated methicillin-resistant Staphylococcus aureus: epidemiology and clinical consequences of an emerging epidemic," Clinical Microbiology Reviews, vol. 23, no. 3, pp. 616-687, 2010.
[11] C. Berglund and B. Söderquist, "The origin of a methicillinresistant Staphylococcus aureus isolate at a neonatal ward in Sweden-possible horizontal transfer of a staphylococcal cassette chromosome mec between methicillin-resistant Staphylococcus haemolyticus and Staphylococcus aureus," Clinical Microbiology and Infection, vol. 14, no. 11, pp. 1048-1056, 2008.

[12] R. R. Watkins, M. Z. David, and R. A. Salata, "Current concepts on the virulence mechanisms of meticillin-resistant Staphylococcus aureus," Journal of Medical Microbiology, vol. 61, no. 9, pp. 1179-1193, 2012.

[13] J. A. McClure-Warnier, J. M. Conly, and K. Zhang, "Multiplex PCR assay for typing of staphylococcal cassette chromosome mec types I to V in methicillin-resistant Staphylococcus aureus," Journal of Visualized Experiments, vol. 79, 2013.

[14] J.-A. McClure, J. M. Conly, V. Lau et al., "Novel multiplex PCR assay for detection of the staphylococcal virulence marker panton-valentine leukocidin genes and simultaneous discrimination of methicillin-susceptible from -resistant staphylococci," Journal of Clinical Microbiology, vol. 44, no. 3, pp. 1141-1144, 2006.

[15] P. Kotilainen, M. Routamaa, R. Peltonen et al., "Eradication of methicillin-resistant Staphylococcus aureus from a health center ward and associated nursing home," Archives of Internal Medicine, vol. 161, no. 6, pp. 859-863, 2001.

[16] N. G. Batina, C. J. Crnich, D. F. Anderson, and D. Döpfer, "Models to predict prevalence and transition dynamics of methicillin-resistant Staphylococcus aureus in community nursing homes," American Journal of Infection Control, vol. 44, no. 5, pp. 507-514, 2016.

[17] A. Van Belkum, M. Vandenbergh, G. Kessie et al., "Genetic homogeneity among methicillin-resistant Staphylococcus Aureus strains from Saudi Arabia," Microbial Drug Resistance, vol. 3, no. 4, pp. 365-369, 1997.

[18] T. A. Madani, N. A. Al-Abdullah, A. A. Al-Sanousi, T. M. Ghabrah, S. Z. Afandi, and H. A. Bajunid, "Methicillinresistant Staphylococcus aureus in two tertiary-care centers in Jeddah, Saudi Arabia," Infection Control \& Hospital Epidemiology, vol. 22, no. 4, pp. 211-216, 2001.

[19] H. A. Bukharie and M. S. Abdelhadi, "The epidemiology of methicillin-resistant Staphylococcus aureus at a Saudi University hospital," Microbial Drug Resistance, vol. 7, no. 4, pp. 413-416, 2001.

[20] N. Tentolouris, G. Petrikkos, N. Vallianou et al., "Prevalence of methicillin-resistant Staphylococcus aureus in infected and uninfected diabetic foot ulcers," Clinical Microbiology and Infection, vol. 12, no. 2, pp. 186-189, 2006.

[21] K. Boye, M. D. Bartels, I. S. Andersen, J. A. Møller, and H. Westh, "A new multiplex PCR for easy screening of methicillin-resistant Staphylococcus aureus SCCmec types I-V," Clinical Microbiology and Infection, vol. 13, no. 7, pp. 725-727, 2007.

[22] H. A. Carleton, B. A. Diep, E. D. Charlebois, G. F. Sensabaugh, and F. Perdreau-Remington, "Community-adapted methicillin-ResistantStaphylococcus aureus (MRSA): population dynamics of an expanding community reservoir of MRSA," The Journal of Infectious Diseases, vol. 190, no. 10, pp. 17301738, 2004.

[23] J. M. Brady, M. E. Stemper, A. Weigel, P.-H. Chyou, K. D. Reed, and S. K. Shukla, "Sporadic "transitional" community-associated methicillin-resistant Staphylococcus aureus strains from health care facilities in the United States," Journal of Clinical Microbiology, vol. 45, no. 8, pp. 2654-2661, 2007. 
[24] P.-L. Ho, T. K. F. Wang, P. Ching et al., "Epidemiology and genetic diversity of methicillin-ResistantStaphylococcus aureus strains in residential care homes for elderly persons in Hong Kong," Infection Control \& Hospital Epidemiology, vol. 28, no. 6, pp. 671-678, 2007.

[25] U. Raab, D. Kahlau, F. Wagenlehner et al., "Prevalence of and risk factors for carriage of panton-valentine leukocidin-positive methicillin-ResistantStaphylococcus aureus among residents and staff of a German nursing home," Infection Control \& Hospital Epidemiology, vol. 27, no. 2, pp. 208-211, 2006.

[26] S. M. Hamilton, A. E. Bryant, K. C. Carroll et al., "In vitro production of panton-valentine leukocidin among strains of methicillin-resistant Staphylococcus aureus causing diverse infections," Clinical Infectious Diseases, vol. 45, no. 12, pp. 1550-1558, 2007.

[27] K. R. Alkharsah, S. Rehman, A. Alnimr, A. Diab, A. Hawwari, and S. Tokajian, "Molecular typing of MRSA isolates by spa and PFGE," Journal of King Saud University-Science, vol. 31, no. 4, pp. 999-1004, 2018. 